\title{
Improved method for assessing iron stores in the bone marrow
}

\author{
K S Phiri, ${ }^{1}$ J C J Calis, ${ }^{1,2}$ D Kachala, ${ }^{1}$ E Borgstein, ${ }^{3}$ J Waluza, ${ }^{3}$ I Bates, ${ }^{4}$ B Brabin, ${ }^{4}$ \\ M Boele van Hensbroek ${ }^{1,2,4}$
}

\begin{abstract}
${ }^{1}$ Malawi-Liverpool-Wellcome
Trust Clinical Research Programme, College of

Medicine, Blantyre, Malawi;

${ }^{2}$ Emma Children's Hospital

AMC, University of Amsterdam, Netherlands; ${ }^{3}$ Department of

Surgery, College of Medicine,

Blantyre, Malawi; ${ }^{4}$ Liverpool

School of Tropical Medicine,

Liverpool, UK
\end{abstract}

Correspondence to:

Dr K Phiri, Malawi-Liverpool-

Wellcome Trust Clinical

Research Programme, PO Box

30096, Blantyre 3, Malawi;

kamijaphiri@gmail.com

Accepted 19 February 2009

\begin{abstract}
Background: Bone marrow iron microscopy has been the "gold standard" method of assessing iron deficiency. However, the commonly used method of grading marrow iron remains highly subjective.

Aim: To improve the bone marrow grading method by developing a detailed protocol that assesses iron in fragments, in macrophages around fragments and in erythroblasts.
\end{abstract}

Methods: A descriptive study of marrow aspirates of 303 children (aged 6-60 months) with severe anaemia and 22 controls (children undergoing elective surgery) was conducted at hospitals in southern Malawi (2002-04).

Results: Using an intensive marrow iron grading method, $22 \%$ and $39 \%$ of cases and controls had deficient iron stores, and $40 \%$ and $46 \%$ had functional iron deficiency, respectively. Further evaluation of the iron status classification by the intensive method showed that functional iron deficiency was associated with significantly increased C-reactive protein concentrations (126.7 (85.6) $\mathrm{mg} / \mathrm{l})$, and iron stores deficiency with significantly increased soluble transferrin receptor concentrations (21.7 (12.5) $\mu \mathrm{g} / \mathrm{ml})$.

Conclusions: Iron assessment can be greatly improved by a more intense marrow examination. This provides a useful iron status classification which is of particular importance in areas where there is a high rate of inflammatory conditions.

Functional iron deficiency develops when normal physiological systems for transporting iron to target tissues are impaired in the presence of satisfactory iron stores. ${ }^{1}$ This is commonly caused by cytokines released during an acute phase response to infection, leading to impaired erythropoiesis and later anaemia, usually termed "anaemia of inflammation".2

Although mass spectrometry has been recently used to give a definitive determination of iron in tissue, ${ }^{34}$ microscopic examination of Prussian bluestained bone marrow aspirate has been considered the practical "gold standard" for determining iron depleted states. ${ }^{56}$ Conventionally, iron has been primarily assessed in marrow fragments which represent iron stores in the form of hemosiderin. ${ }^{78}$ Although some studies have shown a reasonable correlation between histological iron grading and chemical iron concentration in bone marrow, ${ }^{89}$ others have not, raising questions about the validity of the histological grading. ${ }^{10}$

Iron visualised in marrow fragments is from a meshwork of reticular cells which are usually undistinguishable. However, single "loose" macrophages may be inspected for iron and it is hypothesised to be particularly important when iron in fragments is absent and may signify the lowest level of iron stores depletion.

In areas where there is a high prevalence of inflammatory conditions, functional iron deficiency commonly occurs. Erythroblast iron may be indicative of cellular iron utilisation and decreased in functional iron deficiency ${ }^{11}$; however there has been little research on the use of erythroblast iron as a marker of cellular iron availability. ${ }^{12}$ Furthermore, in malaria endemic areas, interpretation of iron status may be confounded by the presence of hemozoin..$^{13} 14$

Recent studies have suggested that it may be detrimental to mass treat children with iron, ${ }^{15}$ so it is important to be able to identify children with iron stores deficiency. The aim of the present study was to determine if a more intensive bone marrow classification can distinguish iron deficiency states in severely anaemic children and their controls living in a malaria endemic area.

\section{METHODS}

This was a descriptive study which was part of a large case-control study investigating the aetiology of severe anaemia in Malawi. Children were recruited between July 2002 and July 2004 at Queen Elizabeth Central hospital in Blantyre and Chikwawa District hospital. ${ }^{16}$

All children who presented to hospital with severe anaemia (haemoglobin of less than $5.0 \mathrm{~g} / \mathrm{dl}$ and no history of being transfused in the preceding four weeks), aged 6-60 months, were eligible for recruitment as cases. A group of children undergoing elective operations with no obvious signs of infection and within the same age range as cases were recruited as "normal" controls. Samples of venous blood and bone marrow aspirate were collected from cases and controls under anaesthesia from either the anterior or posterior iliac crest. The first few drops of a bone marrow aspirate were collected in an EDTA tube for smear preparation. ${ }^{16}$

Written informed consent was obtained from the guardians of the children and the study was approved by the ethics committees of the University of Malawi and the Liverpool School of Tropical Medicine, UK.

\section{Bone marrow smear preparation}

Bone marrow smears were air-dried before being fixed in methanol for 5 minutes. Iron staining was done at the Wellcome Trust laboratories, Blantyre, using a commercial kit and according to methods recommended by the manufacturer (HematoGnost is paper is freely aval 
Fe, Darmstadt, Germany). Positive controls were included in each batch of slides.

\section{Bone marrow smear iron grading}

Bone marrow smears were graded by the conventional Gale's method and by a new more intensive grading method.

Marrow smears were first assessed by one of the authors (KP) according to Gale's histological grading $\operatorname{method}^{8}$ which assesses only marrow fragments (table 1). In order to reduce subjectivity, predefined descriptions and sample illustrations of each iron grade were used to grade fragments of all marrow smears. Only iron smears with at least seven fragments were assessed. ${ }^{17}$ Deficiency of iron stores was defined as an iron grade of none (grade 0 ) or very slight (grade 1).

All marrow smears were then systematically assessed using an intensive histological grading method in which iron is assessed in three sites - the fragments (as in Gale's method), macrophages and erythroblasts. Iron assessed in the fragments and macrophages represented iron stores while iron in the erythroblast represented utilisable iron. Additionally, 20 fields around and behind the fragments were examined at high power $(\times 1000)$ and all macrophages in these fields were examined for the presence of iron (fig 1). At high power magnification $(\times 1000), 100$ erythroblasts were examined and the percentage containing iron granules in their cytoplasm (ie, sideroblasts) were enumerated. Erythroblast iron deficiency was defined when $<30 \%$ of erythroblasts had visible iron granules. ${ }^{18}$

Results of iron smear assessment using the intensive histological grading method were interpreted as normal status (normal iron stores and normal erythroblast iron); functional iron deficiency (normal iron stores and deficient erythroblast iron); iron stores deficiency (depleted iron stores and normal erythroblast iron); and combined functional iron and iron stores deficiency (depleted iron stores and deficient erythroblast iron; table 2).

\section{Other laboratory tests}

Bone marrow iron status assessment was compared to peripheral blood iron markers from samples taken at the same time as the bone marrow aspirate. Haemoglobin was measured using a Coulter counter machine (Beckman Coulter, Durban, South Africa). Ferritin, a measure of iron stores deficiency, was determined using the electrochemiluminescence immunoassay (Modular Analytics E170, Roche Diagnostics, Switzerland), and soluble transferrin receptor (sTfR) levels, a measure of cellular iron need, using ELISA (Ramco Laboratories, Texas, USA). Immunoturbidimetric assay (Modular P800, Roche Diagnostics, Switzerland) was used to determine C-reactive protein (CRP) levels (measure of inflammation) in blood.

Table 1 Histological grading for bone marrow iron status according to Gale et $a l^{8}$

\begin{tabular}{|c|c|c|}
\hline Grade 0 & None & No visible iron under high power magnification $(\times 1000)$ \\
\hline Grade 1 & Very slight & $\begin{array}{l}\text { Small iron particles just visible in few reticulum cells under } \\
\text { high power magnification }(\times 1000)\end{array}$ \\
\hline Grade 2 & Slight & $\begin{array}{l}\text { Small, sparsely distributed iron particles just visible under } \\
\text { low power magnification }(\times 100)\end{array}$ \\
\hline Grade 3 & Moderate & $\begin{array}{l}\text { Numerous small iron particles present in reticulum cells } \\
\text { throughout the marrow fragment }(\times 100)\end{array}$ \\
\hline Grade 4 & $\begin{array}{l}\text { Moderate } \\
\text { heavy }\end{array}$ & $\begin{array}{l}\text { Larger iron particles throughout the fragment with tendency } \\
\text { to aggregate into clumps }(\times 100)\end{array}$ \\
\hline Grade 5 & Heavy & Dense, large clumps of iron throughout the fragment $(\times 100)$ \\
\hline Grade 6 & Very heavy & $\begin{array}{l}\text { Very large deposits of iron, both intra- and extra-cellular, } \\
\text { obscuring cellular detail in the fragment }(\times 100)\end{array}$ \\
\hline
\end{tabular}

Table 2 Classification of iron status using the intensive grading method

\begin{tabular}{llll}
\hline \multicolumn{2}{l}{ Iron detected in: } & & \\
\cline { 1 - 2 } Fragment* & Macrophage $\dagger$ & Erythroblast; & Iron status category \\
\hline Present & Present & Present & Normal \\
Present & - & Present & \\
Present & Present & - & Functional iron deficiency \\
Present & - & - & \\
- & Present & Present & Iron stores deficiency \\
- & - & Present & \\
- & Present & - & Functional and iron stores \\
- & - & - & deficiency
\end{tabular}

*Positive fragment iron: fragment grade $\geqslant 2$.

Positive macrophage iron: iron present in reticular cell.

fPositive erythroblast iron: iron present in $>30 \%$ of erythroblasts. 
Table 3 Baseline characteristics of cases and controls

\begin{tabular}{|c|c|c|}
\hline Characteristic & Cases & Controls \\
\hline Recruited & 381 & 23 \\
\hline Age (years)* & $1.7(1.1)(371)$ & $1.8(0.9)(21)$ \\
\hline $\mathrm{Hb}(\mathrm{g} / \mathrm{dl})^{*}$ & $3.6(0.8)(381)$ & $9.9(1.8)(23)$ \\
\hline Male & 178/381 (46.7\%) & 19/22 (86.4\%) \\
\hline History of previous transfusion & $57 / 378(15.1 \%)$ & $0 / 23(0 \%)$ \\
\hline Wasted $\dagger$ & $53 / 330(16.1 \%)$ & $3 / 16(18.8 \%)$ \\
\hline Stunted $\$$ & $176 / 331$ (53.2\%) & $7 / 17(41.2 \%)$ \\
\hline Malaria§ & $226 / 380(59.5 \%)$ & $0 / 23(0 \%)$ \\
\hline HIV & 45/357 (12.6\%) & $0 / 9(0 \%)$ \\
\hline Bacteraemia** & $54 / 359(15.0 \%)$ & $1 / 14(7.1 \%)$ \\
\hline
\end{tabular}

${ }^{*}$ Mean (SD) (total no).

$\nmid Z$-score $<-2$ weight-for-height.

$\$$ Z-score $<-2$ height-for-age.

§Presence of Plasmodium falciparum asexual parasites in blood.

- Positive for two rapid tests according to WHO guidelines. Discordant results and reactive results in children less than 18 month were resolved by PCR. ${ }^{19}$

**Presence of pathogenic bacteria using an automated BacT/Alert system

(BioMerieux, Missouri, USA) and cultured for 5 and 56 days for routine pathogens and mycobacteria, respectively.

\section{RESULTS}

A total of 381 cases and 23 controls were recruited. Cases had an average age of 1.7 years (SD 1.1), and 46.7\% (178/381) were male; controls had an average age of 1.8 years (SD 0.9) and $86.4 \%(19 / 22)$ were male. Death in-hospital occurred in $6.3 \%$ $(24 / 381)$ of cases, with no deaths in controls (table 3 ).

Of a total of 381 cases, 334 bone marrow aspirations were attempted, from which 303 marrow smears were prepared (fig 2). Forty-seven (12\%) cases did not have a bone marrow aspiration for the following reasons: refusal by guardian, child being too sick, unsuccessful aspiration. Twenty-two of 23 (96\%) controls had a bone marrow aspirate collected and smear prepared. Therefore 303 case smears and 22 control smears were available for assessment.

\section{Gale's grading method}

From the total smears considered for assessment, 66 of 303 $(22 \%)$ cases and 4 of 22 (18\%) controls were not assessed because they contained inadequate bone marrow fragments for proper assessment. Assessment of the remaining smears showed that iron deficiency was present among 33.8\% (80/237) of cases and $61.1 \%(11 / 18)$ of controls. According to conventional grading, iron stores deficiency was more frequent among the controls than cases, but this difference was not significant (OR $=1.8,95 \%$ CI 0.8 to 4.25 ).

\section{Intensive grading method}

Staining quality was adequate to enable assessment of macrophage and erythroblast iron in $79 \%$ of cases $(187 / 237)$ and $72 \%$ of controls (13/18). Cases and controls were classified into different iron status categories depending on iron assessment in fragment, macrophage and erythroblast as shown in table 4. Functional iron deficiency was the most common iron status category among both cases $(39.6 \% ; 74 / 187)$ and controls $(46.2 \% ; 6 / 13)$. Iron stores deficiency was less frequent among cases $(21.9 \%$; $41 / 187)$ than controls $(38.5 \% ; 5 / 13 ; p=0.2)$.

Categories of iron status classified by the intensive grading method were compared with values for peripheral blood markers of iron stores (fig 3). Low levels of ferritin and high levels of sTfR signify deficiency of iron stores in the absence of inflammation. ${ }^{20}$ Mean ferritin concentration was lower in
Figure 2 Flow chart showing the number of children recruited and the number of bone marrow samples finally assessed using both Gale's and intensive histological grading methods.

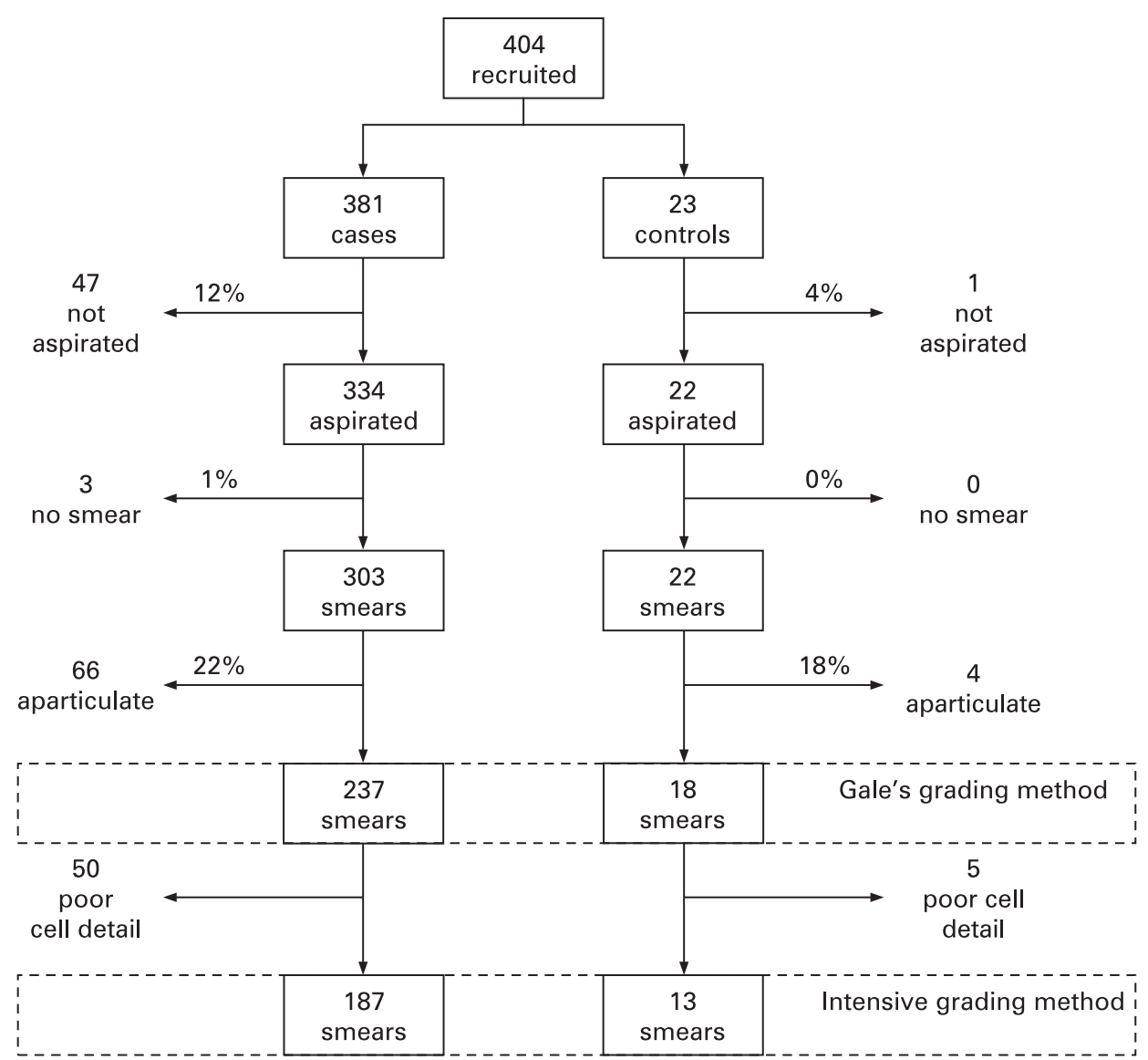


Table 4 Bone marrow iron status category results using the ntensive grading method

\begin{tabular}{|c|c|c|c|c|}
\hline Iron status category & $\begin{array}{l}\text { Cases } \\
(n=187)\end{array}$ & $\begin{array}{l}\text { Controls } \\
(\mathrm{n}=13)\end{array}$ & $0 R^{*}(95 \% \mathrm{CI})$ & p Value \\
\hline Functional iron deficiency (\%) & 39.6 & 46.2 & $0.7(0.2$ to 2.9$)$ & 0.9 \\
\hline Normal iron (\%) & 31.0 & 7.7 & $5.4(0.8$ to 234.6$)$ & 0.1 \\
\hline Iron stores deficiency (\%) & 21.9 & 38.5 & $0.5(0.1$ to 1.9$)$ & 0.2 \\
\hline $\begin{array}{l}\text { Functional and stores deficiency } \\
(\%)\end{array}$ & 7.5 & 7.7 & $1.0(0.1$ to 44.4$)$ & 0.9 \\
\hline
\end{tabular}

children with deficiency of iron stores $(1.9$ (SD 0.7) $\mu \mathrm{g} / \mathrm{l})$ than in those with no deficiency (2.8 (SD 0.5) $\mu \mathrm{g} / \mathrm{l}, \mathrm{p}=0.05$ ), or with functional iron deficiency (2.6 (SD 0.6) $\mu \mathrm{g} / \mathrm{l}, \mathrm{p}<0.001)$. Children with deficiency of iron stores had a higher mean concentration of sTfR (21.7 (SD 12.5) $\mu \mathrm{g} / \mathrm{l})$ than those with normal iron stores (12.5 (SD 16.2) $\mu \mathrm{g} / 1, \mathrm{p}<0.001$ ), or functional iron deficiency (11.4 (SD 6.0) $\mu \mathrm{g} / \mathrm{l}, \mathrm{p}<0.001$ ). Children with functional iron deficiency had increased mean levels of CRP (126.7 (SD 85.6) $\mathrm{mg} / \mathrm{l}$ ) compared to those with iron stores deficiency (71.9 (SD 74.7) mg/l, $\mathrm{p}<0.001$ ), or normal iron status (99.8 (SD 70.1) mg/l, $\mathrm{p}=0.01)$.

Ferritin, sTfR and CRP were determined for normal iron and iron deficiency states classified by Gale's grading method (table 5). Mean log ferritin was higher in those with normal status cases compared to those who were iron deficient. The converse was true for mean sTfR levels. Mean CRP levels were increased in children with normal iron status compared to those classified as iron deficient $(p<0.001)$.

\section{DISCUSSION}

The intensive histological grading method attempts to distinguish four different iron states compared to the two categories using Gale's method. The ability to distinguish states in which there is decreased cellular iron delivery to erythroblasts in the presence of adequate iron stores (termed functional iron deficiency), compared to states with limited availability due to lack of available iron in the reticular endothelial system, is of particular importance in areas of high malaria transmission and infection. Although some of the results of the biochemical tests are lacking and some of the aspirates were too poor to examine for iron, this study managed to assess a substantive number of bone marrow aspirates. There were no identifiable reasons for selection bias for the missing results.

Functional iron deficiency, classified using the intensive histological grading method, was based on marrow findings alone. Although levels of CRP, a marker of an acute phase response, ${ }^{22}$ were mostly increased in all children, the finding of
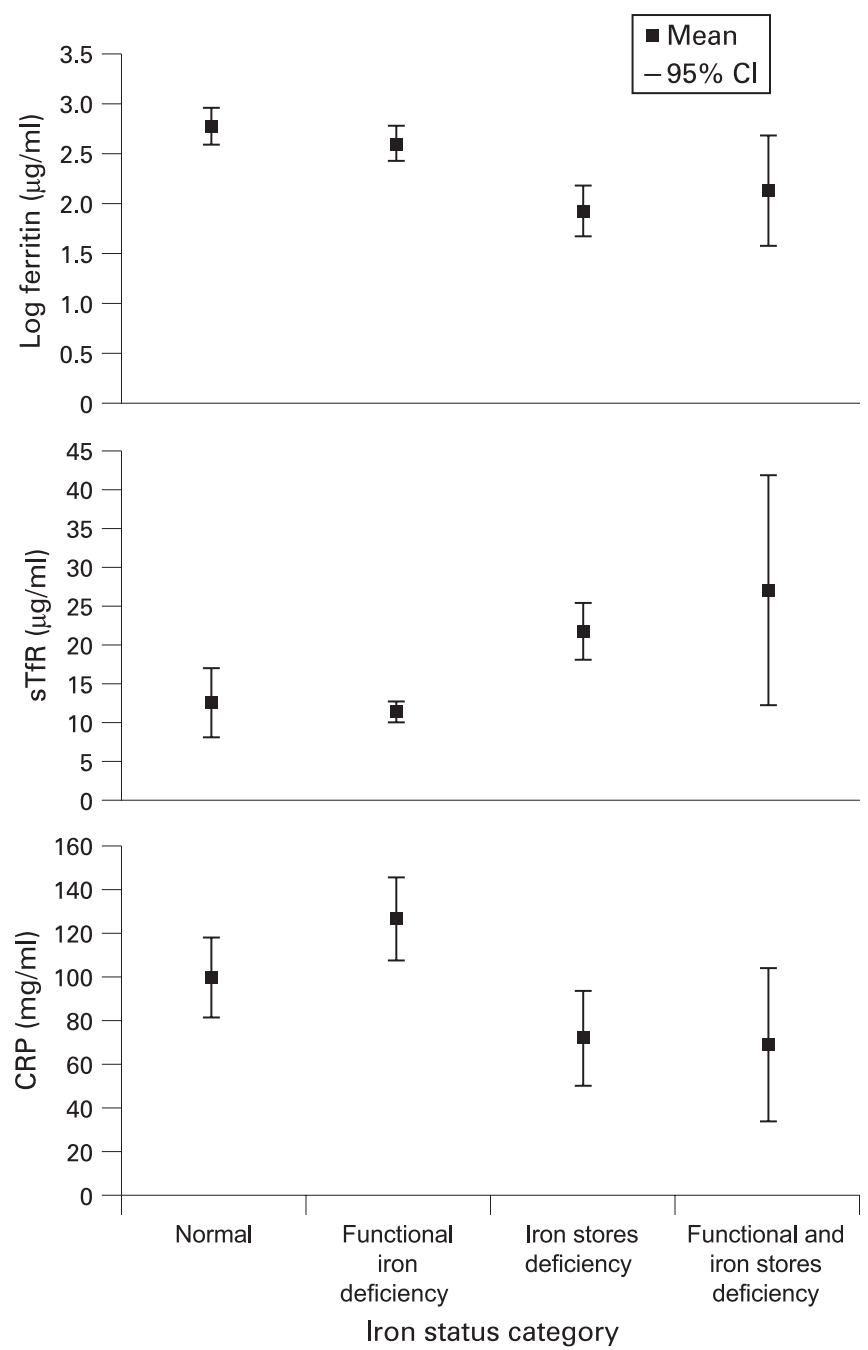

Figure 3 Error bar graphs for mean log ferritin, soluble transferrin receptor (sTfR) and C-reactive protein (CRP) concentrations for the different iron status classes using the intensive grading method.

significantly raised levels among children with functional iron deficiency supports the hypothesis that these children have anaemia of inflammation. These children appeared also to have adequate iron stores as they had similar levels of ferritin and sTfR to children with normal iron status.

The use of erythroblast iron to assess iron status has been used in other studies ${ }^{11}{ }^{18}$ and has certain limitations. Marrow smears were counter-stained with Safranin, giving a uniform

Table 5 Mean levels of Log ferritin, sTfR and CRP for iron status categories using Gale's and Intensive grading methods

\begin{tabular}{|c|c|c|c|c|c|c|c|}
\hline \multirow[b]{2}{*}{ Biochemical tests } & & \multicolumn{2}{|c|}{ Gales' grading method } & \multicolumn{4}{|c|}{ Intensive grading method } \\
\hline & & Normal & Iron deficiency & Normal & $\begin{array}{l}\text { Functional iron } \\
\text { deficiency }\end{array}$ & $\begin{array}{l}\text { Iron stores } \\
\text { deficiency }\end{array}$ & $\begin{array}{l}\text { Functional and iron } \\
\text { stores deficiency }\end{array}$ \\
\hline \multirow[t]{2}{*}{ Log ferritin $(\mu \mathrm{g} / \mathrm{l})^{*}$} & Mean (SD) [n] & $2.7(0.5)$ [89] & $1.8(0.7)[61]$ & $2.8(0.5)[34]$ & $2.6(0.6)[44]$ & $1.9(0.7)[29]$ & $2.1(0.8)^{9}$ \\
\hline & $95 \% \mathrm{Cl}$ & 2.6 to 2.8 & 1.6 to 2.0 & 2.6 to 2.96 & 2.4 to 2.8 & 1.7 to 1.2 & 1.6 to 2.7 \\
\hline \multirow[t]{2}{*}{$\operatorname{sTfR}(\mu \mathrm{g} / \mathrm{ml}) \dagger$} & Mean (SD) [n] & $11.8(10.7)[156]$ & $22.7(15.9)[86]$ & $12.5(16.2)[56]$ & $11.4(6.0)[76]$ & $21.7(12.5)[44]$ & $27.0(28.3)^{14}$ \\
\hline & $95 \% \mathrm{Cl}$ & 10.1 to 13.5 & 19.4 to 26.1 & 8.1 to 17.0 & 10.0 to 12.7 & 18.0 to 25.4 & 12.2 to 41.9 \\
\hline \multirow[t]{2}{*}{$\mathrm{CRP}(\mathrm{mg} / \mathrm{ml}) \neq$} & Mean (SD) [n] & $122.0(6.7)[156]$ & $71.9(8.5)[86]$ & $99.8(70.1)[56]$ & $126.7(85.6)[77]$ & $71.9(74.7)[45]$ & $68.9(64.9)^{13}$ \\
\hline & $95 \% \mathrm{Cl}$ & 108.7 to 135.2 & 55.2 to 88.7 & 81.5 to 118.2 & 107.6 to 145.8 & 50.0 to 93.7 & 33.6 to 104.2 \\
\hline
\end{tabular}

${ }^{*}$ Normal $>30 \mu \mathrm{g} / \mathrm{l}$.

†Normal $<8.3 \mu \mathrm{g} / \mathrm{ml}$.

\#ormal $<10 \mathrm{mg} / \mathrm{ml}$.

sTfR, soluble transferrin receptor; CRP, C-reactive protein. 


\section{Take-home messages}

- Differentiation between functional iron deficiency and quantitative deficiency of iron stores is difficult, especially in areas of high infection pressure.

- A new method of grading of iron content of fragments, macrophages and erythroblasts in the bone marrow is able to distinguish between functional and quantitative iron deficiency in anaemic children.

- Severely anaemic Malawian children have less quantitative iron deficiency than controls without severe anaemia.

pink background colour, which makes visualisation of cell types difficult, and hence may affect erythroblast iron assessment. The use of haematoxylin, or May-Grünwald-Giemsa, for counter-staining smears has been recommended as this provides improved cellular detail. ${ }^{18}$ Tham and Macon $^{23}$ demonstrated that use of a silver stain to visualise erythroblast iron was more sensitive than Perls' stain. However, the precise chemical basis for the silver staining is still unclear.

Some researchers have described erythroblast iron assessment in comparison to simply counting erythroblasts with iron. Baumgartner-Staubli and Beck ${ }^{11}$ developed a "sideroblast score" which assigned an arbitrary value, ranging from 1 to 4 depending on the amount and morphology of iron granules, to each erythroblast with iron. This gave a poor correlation between the sideroblast score and the marrow iron stores assessed using Gale's grading method.

The Malawi Ministry of Health does not have guidelines on whether to give iron in the management of children with severe anaemia. In practice, most children are prescribed iron, however it is often unavailable and the compliance is poor. This study has shown that approximately $30 \%$ of severely anaemic children had deficiency of iron stores (table 3 ) requiring iron treatment. Methods to identify these children are required in poor-resource settings that are based on simple, less invasive procedures than detailed marrow examination. Additionally this study observes a lower prevalence of deficiency of iron stores among severely anaemic children than controls. This phenomenon is not fully understood, but may support the hypothesis that iron deficiency is associated with decreased risk of infection. ${ }^{24}$

This study of a large sample of bone marrow aspirates demonstrates that using an enhanced bone marrow slide assessment provides more detailed information which allows a more precise iron status classification.

Acknowledgements: Special thanks are extended to Barbara Bain, Imperial College School of Medicine, and to the children and their guardians who participated in this study.
Funding: The study was supported by the Wellcome Trust, Gates Malaria Partnership, and Numico and Ter Meulen Foundation.

Competing interests: None.

Ethics approval: Ethics approval was obtained.

\section{REFERENCES}

1. Roy CN, Andrews NC. Anemia of inflammation: the hepcidin link. Curr Opin Hematol 2005;12:107-11.

2. Trey JE, Kushner I. The acute phase response and the hematopoietic system: the role of cytokines. Crit Rev Oncol Hematol 1995;21:1-18.

3. Helliwell T, Kelly $\mathrm{S}$, Walsh $\mathrm{H}$, et al. Elemental analysis of femoral bone from patients with fractured neck of femur or osteoarthrosis. Bone 1996;18:151-7.

4. van Dieijen-Visser MP, Marell GJ, Coenen JL, et al. Quantitative determination of nonhaem iron and ferritin iron in bone marrow using flameless atomic absorption spectrophotometry. A comparative study on the cytological and chemical determination of the bone marrow iron content. Eur J Clin Chem Clin Biochem 1991;29:381-4.

5. Burns E, Goldberg S, Lawrence C, et al. Clinical utility of serum tests for iron deficiency in hospitalized patients. Am J Clin Pathol 1990;93:240-5.

6. Intragumtornchai T, Rojnukkarin P, Swasdikul D, et al. The role of serum ferritin in the diagnosis of iron deficiency anaemia in patients with liver cirrhosis. J Intern Med 1998;243:233-41.

7. Finch CA, Huebers $H$, Eng $M$, et al. Effect of transfused reticulocytes on iron exchange. Blood 1982;59:364-9.

8. Gale E, Torrence J, Bothwell T. The quantitative estimation of total iron stores in human bone marrow. J Clin Invest 1963;42:1076-82.

9. Johansson SV, Plantin LO, Strandberg PO, et al. Estimation of iron in human bone marrow with histological, chemical and neutron activation analysis. Clin Chim Acta 1970;30:549-58.

10. Trubowitz S, Miller WL, Zamora JC. The quantitative estimation of non-heme iron in human marrow aspirates. Am J Clin Pathol 1970;54:71-7.

11. Baumgartner-Staubli R, Beck EA. Sideroblast score: a sensitive indicator of iron deficiency and hypoproliferative anemia. Acta Haematol 1977;57:24-31.

12. Hanif $\mathbf{E}$, Ayyub $\mathrm{M}$, Anwar $\mathrm{M}$, et al. Evaluation of serum transferrin receptor concentration in diagnosing and differentiating iron deficiency anaemia from anaemia of chronic disorders. J Pakistan Med Assoc 2005;55:13-6

13. Rodriguez $\mathbf{M H}$, Jungery M. A protein on Plasmodium falciparum-infected erythrocytes functions as a transferrin receptor. Nature 1986;324:388-91.

14. Sullivan DJ. Theories on malarial pigment formation and quinoline action. Int J Parasitol 2002;32:1645-53.

15. Sazawal S, Black RE, Ramsan M, et al. Effects of routine prophylactic supplementation with iron and folic acid on admission to hospital and mortality in preschool children in a high malaria transmission setting: community-based, randomised, placebo-controlled trial. Lancet 2006;367:133-43.

16. Calis J, Phiri K, Faragher B, et al. Aetiology of severe anemia in Malawian children. N Engl J Med 2008;358:888-99.

17. Hughes DA, Stuart-Smith SE, Bain BJ. How should stainable iron in bone marrow films be assessed? J Clin Pathol 2004;57:1038-40.

18. Hastka J, Lasserre JJ, Schwarzbeck A, et al. Zinc protoporphyrin in anemia of chronic disorders. Blood 1993;81:1200-4.

19. Molyneux EM, Tembo M, Kayira K, et al. The effect of HIV infection on paediatric bacterial meningitis in Blantyre, Malawi. Arch Dis Child 2003;88:1112-8.

20. Pippard MJ, Hoffbrand AV. Iron. In: Hoffbrand AV, Lewis SM, Tuddenham EGD, eds. Postgraduate haematology, 4th edn. Oxford: Butterworth-Heinemann, 1999:23-46.

21. Beguin $\mathbf{Y}$, Huebers HA, Josephson B, et al. Transferrin receptors in rat plasma. Proc Natl Acad Sci USA 1988;85:637-40.

22. Gabay C, Kushner I. Acute-phase proteins and other systemic responses to inflammation. N Engl J Med 1999;340:448-54.

23. Tham KT, Cousar JB, Macon WR. Silver stain for ringed sideroblasts. A sensitive method that differs from Perls' reaction in mechanism and clinical application. Am J Clin Pathol 1990;94:73-6.

24. Murray MJ, Murray AB, Murray MB, et al. The adverse effect of iron repletion on the course of certain infections. BMJ 1978;2:1113-5. 